\title{
Genomic Instability in Chronic Airway Inflammatory Diseases
}

\author{
Zhengqiang Bao ${ }^{1}$, Juan Xiong ${ }^{2}$, Wen $\mathrm{Li}^{2}$, Zhihua Chen ${ }^{2}$, Huahao Shen ${ }^{2,3}$, Songmin Ying ${ }^{1,2}$
}

\begin{abstract}
Chronic airway inflammatory diseases are life-threatening conditions, including bronchial asthma, chronic obstructive pulmonary disease (COPD), and so on. However, as the disease etiology remains largely unclear, current treatments that target chronic airway inflammatory diseases are still not satisfactory. DNA damage response (DDR), regarded as one of the many causes of apoptosis and cell senescence, as well as a factor involved in carcinogenesis, has recently begun to attract attention as a source of chronic inflammation. Considering that COPD and allergic asthma
\end{abstract}

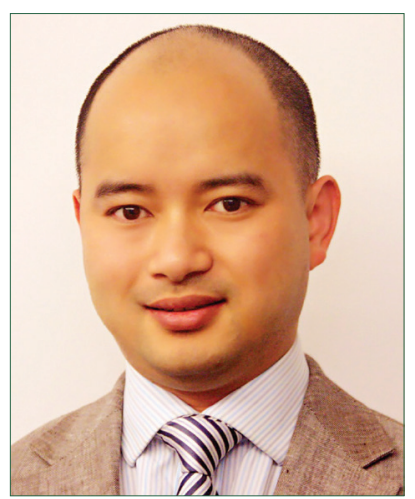

Dr. Songmin Ying

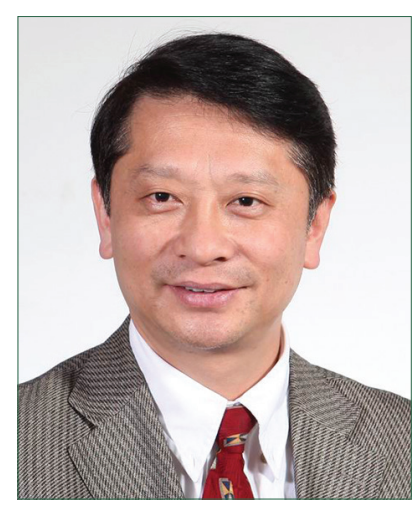

Dr. Huahao Shen inflammation enhance DNA damage, measures related with DNA repair should be taken so as to reduce the injuries caused by these airway diseases. Small molecule inhibitors specifically against various DNA repair proteins have been developed over the last decade to fight against chronic diseases. Poly(ADP-ribose) polymerase (PARP) inhibitor, for example, has already shown its potential in asthma animal models to block airway inflammation. In this review, we highlight the roles of DDR in chronic airway inflammatory diseases, and try to have a better understanding of these diseases. We also discuss the possibilities of targeting DDR signaling to develop potential novel treatments against these conditions. (Biomed J 2015;38:117-124)

\section{Key words: asthma, chronic obstructive pulmonary disease, deoxyribonucleic acid repair, deoxyribonucleic acid damage response, genomic stability}

$\mathrm{C}$ hronic airway inflammatory diseases are life-threatening conditions, including bronchial asthma, chronic obstructive pulmonary disease (COPD), etc., which impact on the quality of life and healthcare expenditure. Asthma is a complex disease involving multiple interactions of genetic and environmental factors. Patients suffering from asthma range widely in age, from teenage children to elderly people. Over 300 million individuals are affected by asthma worldwide, of which there are at least 35 million patients in the United States alone. ${ }^{[1]}$ COPD is highly prevalent and a significant cause of morbid- ity and mortality, which affects more than 200 million people globally. ${ }^{[2]}$ It is expected to be the third leading cause of death worldwide in 2020. ${ }^{[3]}$ However, as the disease etiology remains largely unclear, current treatments that target chronic airway inflammatory diseases are still not satisfactory.

Human genomic DNA is constantly exposed to various endogenous and exogenous stress factors, where genome integrity has continuously been threatened. DNA damage constantly takes place under these conditions by free radicals and other reactive compounds produced during metabolism,

\footnotetext{
*ZB and JX contributed equally.

From the ${ }^{1}$ Department of Pharmacology, Zhejiang University School of Medicine, Hangzhou, China; ${ }^{2}$ Department of Respiratory and Critical Care Medicine, Second Affiliated Hospital, Institute of Respiratory Diseases, Zhejiang University School of Medicine, Hangzhou, China; ${ }^{3}$ State Key Lab for Respiratory Diseases, Guangzhou, China

Received: Feb. 11, 2014; Accepted: Sep. 12, 2014

Correspondence to: Dr. Songmin Ying, Department of Respiratory and Critical Care Medicine, Second Affiliated Hospital, Institute of Respiratory Diseases, Zhejiang University School of Medicine, Hangzhou, China. 866 Yuhangtang Rd., Hangzhou, Zhejiang 310058, China. Tel: 86-571-8820-8059; Fax; 86-571-8778-3729; E-mail: yings@zju.edu.cn

Correspondence to: Dr. Huahao Shen, Department of Respiratory and Critical Care Medicine, Second Affiliated Hospital, Institute of Respiratory Diseases, Zhejiang University School of Medicine, Hangzhou, China. 866 Yuhangtang Rd., Hangzhou, Zhejiang 310058, China. Tel: 86-5718820-8059; Fax; 86-571-8778-3729; E-mail:huahaoshen@zju.edu.cn
}

DOI: $10.4103 / 2319-4170.143478$ 
errors happening in DNA replication and recombination, ultraviolet (UV) and ionizing irradiation from the environment, some harmful chemicals, and so on. Therefore, cells are often under constant assault by endogenous and environmental DNA damaging agents. It is estimated that approximately 10 DNA double-strand breaks (DSBs) are formed daily in one individual mammalian cell. ${ }^{[4]}$ DNA damage response (DDR), regarded as one of the many causes of apoptosis and cell senescence, as well as a factor of carcinogenesis, has recently begun to attract attention as a source of chronic inflammation.$^{[5-11]}$ Frequent DNA damage may increase the mutation rate and genomic instability, which is in most cases fixed by a variety of DNA repair mechanisms. An essential and first step to initiate DNA repair is to block the cell cycle progression and prevent the cycle events that might aggravate the adverse effects of DNA damage and allow repairing.

Inflammation is a protective response to cellular and tissue damage or injury, and also the main feature of COPD and asthma, the two typical chronic airway inflammatory diseases. However, when this beneficial response occurs in an uncontrolled manner, it causes excessive cellular and tissue damage that results in chronic inflammation and destruction of normal tissue. ${ }^{[12,13]}$ Since human airway is an open system, once exposed to cigarette smoke, gases, or other noxious particles, the epithelial cells are activated to produce inflammatory mediators. Reactive oxygen species (ROS) are one of the most important mediators. Excessive production of ROS is commonly thought to be responsible for a range of respiratory inflammatory diseases, including COPD and asthma. It has been suggested that ROS induces DNA damage in airway inflammation. ${ }^{[14,15]}$

In this review, we highlight the role of DDR in chronic airway inflammatory diseases, and try to have a better understanding of these diseases at a molecular level. We also discuss the possibilities of targeting DDR signaling to develop potential novel treatments against these conditions.

\section{Types of DNA damage and repair defects in COPD}

\section{DNA DSBS}

Smoking is known to be highly associated with COPD, which has been reported to be one of the most important environmental factors that cause DNA damage. ${ }^{[16-18]}$ Also, DSBs are among the most dangerous forms of DNA damage caused by smoking. ${ }^{[19]}$ DSBs had been detected in peripheral blood mononuclear leukocytes of COPD patients, and it had been proved that elevated levels of DNA damage are strongly associated with smoking COPD patients than with random COPD patients. ${ }^{[20]}$ When DSBs are induced, the histone $\mathrm{H} 2 \mathrm{AX}$ becomes rapidly phosphorylated at serine 139 , the so-called $\gamma-\mathrm{H} 2 \mathrm{AX}$. Following activation by phosphorylation, $\gamma-\mathrm{H} 2 \mathrm{AX}$ serves as a reliable and sensitive indicator for DSBs because it is activated and recruited to the damage loci at a very early stage and can be easily visualized by staining with antibodies. ${ }^{[21-24]}$ Following phosphorylation and recruitment at DSBs, $\gamma-\mathrm{H} 2 \mathrm{AX}$ further recruits other DNA repair proteins, including $\mathrm{p} 53$-binding protein (53BP) 1 and BRCA1, resulting in activation of distinctive downstream repair pathways. By immunofluorescence staining of these particular proteins, researchers found that alveolar type I, type II cells, and endothelial cells in patients with COPD showed higher levels of DDR at DSBs than those found in asymptomatic smokers and non-smokers. ${ }^{[25]}$

\section{Somatic DNA alterations}

Microsatellite DNA instability (MSI) has been correlated with a high somatic mutation rate and is associated with deficiency of DNA mismatch repair. ${ }^{[26,27]}$ It was reported in 1999 that MSI was found exclusively in the sputum cells of smokers with COPD, which indicated that genetic alteration might increase susceptibility to COPD ${ }^{[28]}$ Another study revealed that MSI was found in 38\% COPD patients (14 out of 36), while none was found in bronchiectasis or control subjects (non-COPD smokers, healthy subjects). ${ }^{[29]}$ Loss of heterozygosity (LOH) was also observed in epithelial barrier cells of COPD patients. LOH was found in D5S207, D6S344, G29802, and D17s250 microsatellite markers, while MSI was found in D13S71, D5S207, and D6S344. ${ }^{[30]}$ A study aimed to investigate the relationship between MSI in sputum cells and exacerbation frequency, and found that 18 out of 36 patients exhibited MSI in their sputum cells, and patients who exhibited MSI showed significantly increased frequency of COPD exacerbations. In addition, a significantly higher frequency of purulent and severe exacerbation was found in patients exhibiting MSI. These results suggested that somatic mutations could be involved in the pathogenesis of the disease. ${ }^{[31]}$

\section{Mitochondrial DNA damage}

Mitochondrial DNA (mtDNA) contributes to oxidation resistance, which is an important determinant that affects COPD susceptibility. It was reported that mtDNA is about 30-fold more sensitive to exogenous oxidants than nuclear DNA ${ }^{[32-34]}$ In order to investigate whether mtDNA damage is involved in COPD susceptibility, the frequencies of mtDNA haplogroups and an 822-bp mtDNA deletion in 671 COPD patients and 724 control individuals were analyzed and compared. The results revealed that mtDNA haplogroups A and $\mathrm{M} 7$ might be risk factors for $\mathrm{COPD}$, whereas haplogroups $\mathrm{D}$, F, and M9 might decrease risk of COPD. Other evidence revealed that skeletal muscle mtDNA and nuclear DNA 
fell significantly after exercise, and the changes were much more obvious in patients with COPD ${ }^{[35]}$ Investigators had detected a basic site and strand breaks in mtDNA in lung tissue from patients with severe COPD. ${ }^{[36]}$

\section{Loss of telomeres}

It seems that COPD is a disease of accelerated aging, and occurs mostly in elderly people. ${ }^{[37]}$ Oxidative stress, an important factor of COPD, has a significant impact on the rate of telomere loss. Telomere shortening is dramatically accelerated (or slowed) in cells with increased (or reduced) levels of oxidative stress. ${ }^{[38]}$ Shortness of telomere length was indicated to be associated with a 28-fold increased risk of COPD. ${ }^{[39]}$ Telomere dysfunction is one of the major processes perpetuating pulmonary inflammation in COPD.$^{[40]}$ COPD patients were reported to have shorter telomeres in leukocytes, out of 46,396 individuals from the Danish general population. Rode et al. found that shortened telomere length was associated with higher risk of COPD, though the association was markedly attenuated after age and multivariable adjustment. ${ }^{[39]}$

\section{Gene polymorphisms}

HOGG1 Ser326Cys and XRCC1 Arg399Gln polymorphisms have been shown to contribute to the susceptibility of COPD, where HOGG1 and XRCC1 genotypes of 201 COPD patients and 309 controls were determined. The results showed that the risk of COPD is significantly elevated among smokers with HOGG1 326Cys and XRCC1 Arg399Gln. ${ }^{[41]}$ In another study on COPD and gene polymorphisms, which was conducted to find the link between genetic polymorphisms in genes XRCC1 (Arg399Gln), OGG1 (Ser326Cys), XRCC3 (Thr241Met), and XRCC4 (lle401Thr) and the level of DNA damage and repair, 51 COPD patients and 51 controls were assessed by comet and micronucleus test, and the results showed that COPD patients with the risk alleles $X R C C 1$ and $X R C C 3$ had higher levels of DNA damage ${ }^{[42]}$ Micronucleus represents a severe form of genomic instability as a result of disrupted faithful segregation of chromosomes during mitosis. ADAM33, a disintegrin and metalloprotease domain 33 gene, has been found to be associated with asthma, and declined lung function in COPD, within which seven single-nucleotide polymorphisms (SNPs) had been demonstrated to be associated with COPD in the Mongolian population of China. ${ }^{[43]}$ However, this was not found to be consistent in certain populations such as Caucasians, where no correlation between ADAM33 polymorphism and COPD was identified. ${ }^{[44]}$ Iron-responsive element-binding protein 2 (IREB2) and mRNA were found to be increased in the lung tissues from COPD patients compared with controls, ${ }^{[45]}$ and evidence suggests that the IREB2 SNPs in association with COPD are SNP rs2568494, rs2656069, and rs12593229. ${ }^{[46]}$ Though COPD is mainly caused by smoking, another investigation found that IREB2 may affect COPD independent of smoking. ${ }^{[4]}$

\section{DNA damage repair response}

DNA repair mechanisms are versatile tools for cells to correct damaged DNA, which include base excision repair, nucleotide excision repair, DSB repair, and cross-link repair. ${ }^{[48]}$ Efficient repair of damaged DNA, particularly DSBs, is essential for the maintenance of chromosomal integrity, ${ }^{[49]}$ as DSBs are among the most serious forms of DNA damage caused by smoking. Impaired DNA repair efficiency is common in COPD. This may be due to the lack of DNA damage repair in both bronchial epithelium and connective tissue induced by heritable genetic polymorphisms. ${ }^{[50,51]}$ Generally, DSBs are repaired either by homologous recombination or by non-homologous end-joining (NHEJ) pathway; in the latter pathway, six distinct proteins (Ku70, Ku80, XRCC4, DNA ligase IV, Artemis, and DNA-dependent protein kinase catalytic subunit (DNA-PKcs) play a major role. ${ }^{[52,53]}$ The damage sites are initially recognized by $\gamma-\mathrm{H} 2 \mathrm{AX}$, which will extend up to several thousand nucleosomes from the actual loci of the DSB and may mark the surrounding chromatin for recruitment of the proteins that are required for the following downstream DDR signaling transduction and repair. ${ }^{[54]}$ XRCC5, also known as Ku80, is an ATP-dependent DNA helicase mapped to chromosome 2q35 and contains 21 exons spanning about $97 \mathrm{~kb}$. XRCC5 is identified as a potential COPD susceptibility gene, by combining data from COPD genetic association studies conducted in four independent patient samples. ${ }^{[55-57]}$

Poly (ADP-ribose) polymerase-1 (PARP-1) is a monomeric nuclear enzyme present in eukaryotes, and its primarily role is to act as a sensor of DNA damage. ${ }^{[58-60]}$ To facilitate DNA repair on damaged DNA loci, PARP-1 becomes highly activated. ${ }^{\left[{ }^{[6,62]}\right.}$ The activated PARP-1 transfers ADP-ribose units from $\mathrm{NAD}^{+}$to a protein acceptor to produce AD-ribose polymers, which will lead to rapid decline of cellular $\mathrm{NAD}^{+}$concentrations and pose a large demand on cellular ATP stores for re-synthesis of NAD ${ }^{+}{ }^{[63]}$ The level of $\mathrm{NAD}^{+}$in cells is considered to play a key role in the control of many fundamental cellular processes. ${ }^{[64]}$ Under conditions of energy crisis, cells undergo necrotic death, further amplifying the inflammatory response. ${ }^{[65]}$ In a patient-control study, 37 stable COPD patients and 21 age-matched healthy volunteers were enrolled. PARP-1 activation was tested by immunofluorescent detection of PAR polymers in peripheral blood lymphocytes. The level of PAR polymer-positive lymphocytes was found to be higher in COPD patients than in healthy controls, and trolox equivalent antioxidant capacity of deproteinized plasma, plasma uric acid, as well as blood $\mathrm{NAD}^{+}$of stable COPD patients were significantly reduced compared to controls. In 
addition, the levels of pro-inflammatory cytokines, such as interleukin (IL)-6, IL-8, and soluble intercellular adhesion molecule-1 (sICAM-1), were found to be increased in COPD patients. Collectively, these data indicated involvement of PARP-1 activation in the pathophysiology of COPD. ${ }^{[66]}$

\section{DDR in asthma}

Asthma, a truly complex disease, is currently considered as a chronic respiratory disorder associated with airway inflammation. Allergic asthma is characterized by increased levels of eosinophils, immunoglobulin (Ig) E, and multiple cytokines [including IL-4, IL-5, IL-9, and tumor necrosis factor (TNF)- $\alpha] \cdot{ }^{[67,68]}$ From the perspective of its pathogenesis, asthma is a result of complicated interactions between genetic and environmental factors, which induce airway inflammation and remodeling ${ }^{[69]}$ Surprisingly, damages in nuclear DNA are correlated with asthmatic inflammation; for example, it was reported that the frequency of spontaneous sister chromatid exchanges (SCEs) was increased in asthmatic patients (AP) compared with control subjects, indicating elevated levels of homologous recombination repair in damaged chromatids. ${ }^{[70]}$ In addition, DNA damage levels in lymphocytes increased significantly in children with asthma. ${ }^{[71]}$ This damage might be related to increased oxidative stress. A study of DNA damage in children with asthma demonstrated that DNA damage parameters and glutathione (GSH) levels were decreased after treatment, which implicated anti-asthmatic therapy could control asthmatic syndrome and, at the meantime, reduce mutation risks in pediatric patients. ${ }^{[72]}$

\section{Abnormality of cell cycle regulation in asthma}

Faithful DNA replication and repair need precisely regulated cell cycle control. Since the asthmatic bronchial epithelium is characterized by widespread damage, researchers postulated that this is associated with deregulation of cell cycle profiles. Expression of p $21^{\text {waf }}$, a cyclin-dependent kinase inhibitor, was shown to be increased in asthmatic bronchial epithelium. ${ }^{[73,74]}$ Analysis of bronchial biopsies from 6 normal subjects without asthma, 14 subjects with mild asthma, and 10 subjects with severe asthma by immunohistochemical staining showed that $\mathrm{P} 21^{\text {waf }}$ expression was significantly higher in asthmatic versus non-asthmatic epithelium. ${ }^{[74]}$ Increased levels of P2 ${ }^{\text {waf }}$ were found not only in adult asthma patients but also in pediatric asthma patients. Immunostaining of intact bronchial epithelium from 23 asthmatic children ( 7 controls, 7 moderate asthma patients, and 9 severe asthma patients) showed that $\mathrm{p} 21^{\text {waf }}$ expression was significantly higher in asthmatic children than in healthy controls. ${ }^{[75]} \mathrm{P} 2^{1 \text { wa }}$ f over-expression was reported to influence cell cycle checkpoint activation, cell proliferation, and survival. Following p53 activation, p21 induction might, in turn, affect DNA repair response that contributes to airway inflammation and remodeling. ${ }^{[73,76]}$

\section{Defects of DNA repair in asthma}

Increased levels of DNA damage in asthma patients are not only a result of high intensity of allergic stress, but also due to reduced ability to fix damaging problems. PARP, a poly-ADP ribose polymerase, is involved in a number of essential cellular processes, including DNA repair and programmed cell death. ${ }^{[77]}$ The widely studied PARP-1 has been implicated in the regulation of distinct biological activities including base excision DNA repair. PARP-1 plays truly a determining role in cell survival in response to DNA damage, ${ }^{[78]}$ and may include damages induced in asthma. Furthermore, increased activation of PARP-1 depletes the cellular stores of NAD and ATP in conditions involving massive DNA damage, which directly induces irreversible cytotoxicity and potential cell death. ${ }^{[79]}$ It was reported that over-activation of PARP by oxidative stress-induced massive DNA damage may exacerbate inflammation. ${ }^{[80]}$ The polymerase chain reaction (PCR)-based restriction analysis of 112 stable asthma patients and 180 normal controls revealed that PARP-1 $762 \mathrm{~V}$ allele had 5 times higher risk of susceptibility to asthma than those without the allele, and PARP-1 762AA genotype conferred only a 3.4-fold reduction in risk while VA genotype conferred an even greater level of protection. ${ }^{[81]}$

\section{Future development of therapy}

In conclusion, severity of DNA damage is a pivotal factor in the development of chronic airway inflammatory diseases (COPD and asthma), which may serve as a molecular link in these diseases. ${ }^{[82]}$ In certain conditions, DNA damage triggers airway inflammation, and therefore causes COPD or asthma, while on the other hand, chronic inflammation may also enhance the levels of DNA damage. Currently, anti-inflammatory treatment is still a major strategy to manage airway inflammatory diseases. It does not seem to be sufficient. Measures related to DNA repair should be taken so as to minimize the injuries caused by these airway diseases. Small molecule inhibitors, especially against various DNA repair proteins, have been developed over the last decade to fight against chronic diseases like cancer. Some of them have shown promising results in killing tumor cells with minimum effects on normal tissues, as little damage occurred in healthy conditions. It remains to be seen if it would be plausible to extend this idea in the management of chronic inflammatory diseases.

PARP inhibitors, for example, have already shown their potential in COPD and asthma patients or animal models in blocking airway inflammation. For instance, it was shown that PARP inhibitor could attenuate lipopolysaccharide (LPS)-induced cytokine (TNF- $\alpha$ and IL-6) release from leukocytes of patients with COPD ${ }^{[83]}$ An in vitro 
study also found that flavone (a PARP-1 inhibitor) could reduce LPS-induced IL-8 production in pulmonary epithelial cells, leading to a hypothesis that PARP-1 inhibitor could have beneficial effects in COPD by preservation of cellular $\mathrm{NAD}^{+}$levels and attenuating inflammatory conditions. ${ }^{[84]}$ Studies based on PARP-1 knockout mice as well as specific PARP inhibitors have indicated that inhibition or genetic ablation of PARP-1 protects asthma mice model from oxidative stress-induced inflammation. ${ }^{[85]}$ In murine models, PARP-1 plays a critical role in the pathogenesis of asthma-related lung inflammation. PARP-1 deficiency leads to increased production of the Th1 cytokines IL-2 and IL-12, but prevents recruitment of eosinophils by modulating Th 2 cytokines, particularly by regulating IL-5 production. ${ }^{[86]}$ Further investigation was carried out to investigate the action of PARP-1 inhibitor (HYDAMTIQ) in the process leading from asthma-like events to airway damage. In the ovalbumin (OVA)- induced asthma model, HYDAMTIQ treatment could reduce lung histological abnormalities, lung oxidative level, and also the lung content of pro-inflammatory cytokines (TNF- $\alpha$, IL-1 $\beta$, IL-5, IL-6, IL-18). ${ }^{[87]}$ These findings support the idea that PARP inhibitors could have a therapeutic potential to reduce chronic airway inflammation, airway damage and remodeling in asthmatic patients.

Another PARP family protein, PARP-14, was also shown to be correlated with asthma. PARP-14 was reported to act as a transcriptional switch for IL-4-dependent signal transducer and activator of transcription 6 (STAT6). ${ }^{[88]}$ IL-4-activated STAT6 is involved in Th2 response and promoting the asthmatic condition, ${ }^{[89-93]}$ thus STAT6 is an attractive therapeutic target for asthma. Further investigation revealed that PARP-14 and its enzyme activity aid in the differentiation of $\mathrm{T}$ cells toward a Th2 phenotype by regulating the binding of STAT6 to the Gata3 promoter. ${ }^{[94]}$ So, it might be a potential new therapy for allergic asthma targeting PARP-14. Exact functions of PARP protein are still very much unknown. It is, therefore, very much needed to clarify whether it is the DNA repair roles of the PARP family proteins that play key functions in these conditions.

Although great progress has been made in the last decades, it is still largely unclear how DDR impacts on chronic airway inflammatory diseases. To eventually improve treatments and alleviate the suffering of patients, more investigations would be required to further fully enhance our understanding of DNA damage response signaling and regulation in chronic airway inflammatory diseases.

\section{Acknowledgments}

We are grateful to Drs. Chao Cao and Hongbin Zhou for critical reading of this manuscript. This work was supported by National 1000 Talents Program for Young
Scholars (SY), National Natural Science Foundation of China (31370901), the Research Funding from Zhejiang Provincial Department of Education (Y201329936), the Fundamental Research Funds for the Central Universities, and the State Key Program of National Natural Science Foundation of China (81130001).

\section{REFERENCES}

1. Mukherjee AB, Zhang Z. Allergic asthma: Influence of genetic and environmental factors. J Biol Chem 2011;286:32883-9.

2. Londahl J, Swietlicki E, Rissler J, Bengtsson A, Boman C, Blomberg A, et al. Experimental determination of the respiratory tract deposition of diesel combustion particles in patients with chronic obstructive pulmonary disease. Part Fibre Toxicol 2012;9:30.

3. Krimmer DI, Oliver BG. What can in vitro models of COPD tell us? Pulm Pharmacol Ther 2011;24:471-7.

4. Gospodinov A, Herceg Z. Chromatin structure in double strand break repair. DNA Repair (Amst) 2013;12:800-10.

5. Sancar A, Lindsey-Boltz LA, Unsal-Kacmaz K, Linn S. Molecular mechanisms of mammalian DNA repair and the DNA damage checkpoints. Annu Rev Biochem 2004;73:39-85.

6. Acosta JC, O’Loghlen A, Banito A, Guijarro MV, Augert A, Raguz S, et al. Chemokine signaling via the CXCR2 receptor reinforces senescence. Cell 2008;133:1006-18.

7. Kuilman T, Michaloglou C, Vredeveld LC, Douma S, van Doorn R, Desmet CJ, et al. Oncogene-induced senescence relayed by an interleukin-dependent inflammatory network. Cell 2008;133:1019-31.

8. Rodier F, Coppe JP, Patil CK, Hoeijmakers WA, Munoz DP, Raza SR, et al. Persistent DNA damage signalling triggers senescence-associated inflammatory cytokine secretion. Nat Cell Biol 2009;11:973-9.

9. Freund A, Orjalo AV, Desprez PY, Campisi JF, Reund A. Inflammatory networks during cellular senescence: Causes and consequences. Trends Mol Med 2010;16:238-46.

10. Kuilman T, Michaloglou C, Mooi WJ, Peeper DS. The essence of senescence. Genes Dev 2010;24:2463-79.

11. Rodier F, Campisi J. Four faces of cellular senescence. J Cell Biol 2011;192:547-56.

12. Lee IT, Yang CM. Inflammatory signalings involved in airway and pulmonary diseases. Mediators Inflamm 2013;2013:791231.

13. Yoshikawa T, Naito Y. The role of neutrophils and inflammation in gastric mucosal injury. Free Radic Res 2000;33:785-94.

14. Kirkham PA, Barnes PJ. Oxidative stress in COPD. Chest 2013;144:266-73.

15. Zuo L, Otenbaker NP, Rose BA, Salisbury KS. Molecular mechanisms of reactive oxygen species-related pulmonary inflammation and asthma. Mol Immunol 2013;56:57-63.

16. Wistuba II, Lam S, Behrens C, Virmani AK, Fong KM, LeRiche J, et al. Molecular damage in the bronchial epithelium of current and former smokers. J Natl Cancer Inst 1997;89:1366-73.

17. Mao L, Lee JS, Kurie JM, Fan YH, Lippman SM, Lee JJ, et al. Clonal genetic alterations in the lungs of current and former smokers. J Natl 
Cancer Inst 1997;89:857-62.

18. Wistuba II, Mao L, Gazdar AF. Smoking molecular damage in bronchial epithelium. Oncogene 2002;21:7298-306.

19. Hecht SS. Progress and challenges in selected areas of tobacco carcinogenesis. Chem Res Toxicol 2008;21:160-71.

20. Ceylan E, Kocyigit A, Gencer M, Aksoy N, Selek S. Increased DNA damage in patients with chronic obstructive pulmonary disease who had once smoked or been exposed to biomass. Respir Med 2006;100:1270-6

21. Mah LJ, El-Osta A, Karagiannis TC. GammaH2AX: A sensitive molecular marker of DNA damage and repair. Leukemia 2010;24:679-86.

22. Bekker-Jensen S, Mailand N. Assembly and function of DNA double-strand break repair foci in mammalian cells. DNA Repair (Amst) 2010;9:1219-28.

23. Bonner WM, Redon CE, Dickey JS, Nakamura AJ, Sedelnikova OA, Solier S, et al. GammaH2AX and cancer. Nat Rev Cancer 2008;8:957-67.

24. Kuo LJ, Yang LX. Gamma-H2AX-a novel biomarker for DNA double-strand breaks. In Vivo 2008;22:305-9.

25. Aoshiba K, Zhou F, Tsuji T, Nagai A. DNA damage as a molecular link in the pathogenesis of COPD in smokers. Eur Respir J 2012;39:1368-76.

26. Aaltonen LA, Peltomaki P, Leach FS, Sistonen P, Pylkkanen L, Mecklin JP, et al. Clues to the pathogenesis of familial colorectal cancer. Science 1993;260:812-6.

27. Kunkel TA. Nucleotide repeats. Slippery DNA and diseases. Nature1993;365:207-8.

28. Siafakas NM, Tzortzaki EG, Sourvinos G, Bouros D, Tzanakis N, Kafatos A, et al. Microsatellite DNA instability in COPD. Chest 1999;116:47-51

29. Tzortzaki EG, Dimakou K, Neofytou E, Tsikritsaki K, Samara K, Avgousti M, et al. Oxidative DNA damage and somatic mutations: A link to the molecular pathogenesis of chronic inflammatory airway diseases. Chest 2012;141:1243-50.

30. Samara KD, TzortzakiE EG, Neofytou E, Karatzanis AD, Lambiri I, Tzanakis N, et al. Somatic DNA alterations in lung epithelial barrier cells in COPD patients. Pulm Pharmacol Ther 2010;23:208-14.

31. Makris D, Tzanakis N, Damianaki A, Ntaoukakis E, Neofytou E, Zervou M, et al. Microsatellite DNA instability and COPD exacerbations. Eur Respir J 2008;32:612-8.

32. Yakes FM, Van Houten B. Mitochondrial DNA damage is more extensive and persists longer than nuclear DNA damage in human cells following oxidative stress. Proc Natl Acad Sci USA 1997;94:514-9.

33. Grishko V, Solomon M, Wilson GL, LeDoux SP, Gillespie MN. Oxygen radical-induced mitochondrial DNA damage and repair in pulmonary vascular endothelial cell phenotypes. Am J Physiol Lung Cell Mol Physiol 2001;280:L1300-8.

34. Ballinger SW, Patterson C, Yan CN, Doan R, Burow DL, Young CG, et al. Hydrogen peroxide- and peroxynitrite-induced mitochondrial DNA damage and dysfunction in vascular endothelial and smooth muscle cells. Circ Res 2000;86:960-6.

35. Zheng S, Wang C, Qian G, Wu G, Guo R, Li Q, et al. Role of mtDNA haplogroups in COPD susceptibility in a southwestern Han Chinese population. Free Radic Biol Med 2012;53:473-81.

36. Pastukh VM, Zhang L, Ruchko MV, Gorodnya O, Bardwell GC, Tuder RM, et al. Oxidative DNA damage in lung tissue from patients with COPD is clustered in functionally significant sequences. Int $\mathrm{J}$ Chron Obstruct Pulmon Dis 2011;6:209-17.

37. Ito K, Barnes PJ. COPD as a disease of accelerated lung aging. Chest 2009;135:173-80.

38. Von Zglinicki T. Oxidative stress shortens telomeres. Trends Biochem Sci 2002;27:339-44.

39. Rode L, Bojesen SE, Weischer M, Vestbo J, Nordestgaard BG. Short telomere length, lung function and chronic obstructive pulmonary disease in 46,396 individuals. Thorax 2013;68:429-35.

40. Amsellem V, Gary-Bobo G, Marcos E, Maitre B, Chaar V, Validire P, et al. Telomere dysfunction causes sustained inflammation in chronic obstructive pulmonary disease. Am J Respir Crit Care Med 2011;184:1358-66.

41. Yang SF, Xu YJ, Xie JG, Zhang ZX. HOGG1 Ser326Cys and XRCC1 Arg399Gln polymorphisms associated with chronic obstructive pulmonary disease. Chin Med J (Engl) 2009;122:960-6.

42. Da Silva AL, Da Rosa HT, Karnopp TE, Charlier CF, Ellwanger JH, Moura DJ, et al. Evaluation of DNA damage in COPD patients and its correlation with polymorphisms in repair genes. BMC Med Genet $2013 ; 14: 93$

43. Tan J, Liu AP, Sun C, Bai YF, Lv F. Association of ADAM33 gene polymorphisms with COPD in the Mongolian population of China. Ann Hum Biol 2014;41:9-14

44. Aierken H, Wang J, Wushouer Q, Shayhidin E, Hu X, Syed I, et al. Polymorphisms of the ADAM33 gene and chronic obstructive pulmonary disease risk: A meta-analysis. Clin Respir J 2014;8:108-15.

45. DeMeo DL, Mariani T, Bhattacharya S, Srisuma S, Lange C, Litonjua A, et al. Integration of genomic and genetic approaches implicates IREB2 as a COPD susceptibility gene. Am J Hum Genet 2009;85:493-502.

46. Chappell SL, Daly L, Lotya J, Alsaegh A, Guetta-Baranes T, Roca J, et al. The role of IREB2 and transforming growth factor beta-1 genetic variants in COPD: A replication case-control study. BMC Med Genet 2011;12:24.

47. Siedlinski M, Tingley D, Lipman PJ, Cho MH, Litonjua AA, Sparrow D, et al. Dissecting direct and indirect genetic effects on chronic obstructive pulmonary disease (COPD) susceptibility. Hum Genet 2013;132:431-41.

48. Sancar A, Lindsey-Boltz L A, Unsal-Kacmaz K, Linn S. Molecular mechanisms of mammalian DNA repair and the DNA damage checkpoints. Annu Rev Biochem 2004;73:39-85.

49. Meek K, Gupta S, Ramsden DA, Lees-Miller SP. The DNA-dependent protein kinase: The director at the end. Immunol Rev 2004;200:132-41.

50. Brody JS, Spira A. State of the art. Chronic obstructive pulmonary disease, inflammation, and lung cancer. Proc Am Thorac Soc 2006;3:535-7.

51. Caramori G, Papi A. Pathogenic link between chronic obstructive pulmonary disease and squamous cell lung cancer. Expert Rev Respir Med 2007;1:171-5.

52. Meek K, Gupta S, Ramsden DA, Lees-Miller SP. The DNA-dependent protein kinase: The director at the end. Immunol Rev 2004;200:132-41. 
53. Meek K, Dang V, Lees-Miller SP. DNA-PK: The means to justify the ends? Adv Immunol 2008;99:33-58.

54. Kinner A, Wu W, Staudt C, Iliakis G. Gamma-H2AX in recognition and signaling of DNA double-strand breaks in the context of chromatin. Nucleic Acids Res 2008;36:5678-94.

55. Hersh CP, Pillai SG, Zhu G, Lomas DA, Bakke P, Gulsvik A, et al. Multistudy fine mapping of chromosome $2 \mathrm{q}$ identifies XRCC5 as a chronic obstructive pulmonary disease susceptibility gene. Am J Respir Crit Care Med 2010;182:605-13.

56. Guo Y, Lin H, Gao K, Xu H, Deng X, Zhang Q, et al. Genetic analysis of IREB2, FAM13A and XRCC5 variants in Chinese Han patients with chronic obstructive pulmonary disease. Biochem Biophys Res Commun 2011;415:284-7.

57. Hersh CP, Pillai SG, Zhu G, Lomas DA, Bakke P, Gulsvik A, et al. Multistudy fine mapping of chromosome $2 \mathrm{q}$ identifies XRCC5 as a chronic obstructive pulmonary disease susceptibility gene. Am J Respir Crit Care Med 2010;182:605-13.

58. De Murcia G, Shall, S. From DNA damage and stress signalling to cell death: Poly ADP-ribosylation reactions. Oxford, England: Oxford University Press; 2000.

59. Szabó C: Cell death: The role of PARP. Boca Raton, Florida, USA: CRC Press; 2000.

60. Virág L, Szabó C. The therapeutic potential of poly (ADP-ribose) polymerase inhibitors. Pharmacol Rev 2002;54:375-429.

61. Lindahl T, Satoh MS, Poirier GG, Klungland A. Post-translational modification of poly (ADP-ribose) polymerase induced by DNA strand breaks. Trends Biochem Sci 1995;20:405-11.

62. Oei SL, Griesenbeck J, Schweiger M. The role of poly (ADP-ribosyl) ation. Reviews of Physiology Biochemistry and Pharmacology, Vol. 131. Springer Berlin: Heidelberg; 1997. p. 127-73.

63. PieperAA, Verma A, Zhang J, Snyder SH. Poly (ADP-ribose) polymerase, nitric oxide and cell death. Trends Pharmacol Sci 1999;20:171-81.

64. Berger F, Ramírez-Hernández MaH, Ziegler M. The new life of a centenarian: Signalling functions of NAD $(\mathrm{P})$. Trends Biochem Sci 2004;29:111-8.

65. Ha HC, Snyder SH. Poly (ADP-ribose) polymerase is a mediator of necrotic cell death by ATP depletion. Proc Natl Acad Sci USA 1999;96:13978-82.

66. Hageman GJ, Larik I, Pennings HJ, Haenen GR, Wouters EF, Bast A. Systemic poly (ADP-ribose) polymerase-1 activation, chronic inflammation, and oxidative stress in COPD patients. Free Radic Biol Med 2003;35:140-8.

67. Barnes PJ, Chung KF, Page CP. Inflammatory mediators of asthma: An update. Pharmacol Rev 1998;50:515-96.

68. Chung KF, Barnes PJ. Cytokines in asthma. Thorax 1999;54:825-57.

69. Davies DE, Wicks J, Powell RM, Puddicombe SM, Holgate ST. Airway remodeling in asthma: New insights. J Allergy Clin Immunol 2003;111:215-25.

70. Lialiaris T, Polyzou A, Mpountoukas P, Tsiggene A, Kouskoukis A, Pouliliou S, et al. Chromosome instability on children with asthma. J Asthma 2009;46:841-4.

71. Zeyrek D, Cakmak A, Atas A, Kocyigit A, Erel O. DNA damage in children with asthma bronchiale and its association with oxidative and antioxidative measurements. Pediatr Allergy Immunol 2009;20:370-6.
72. Hasbal C, Aksu BY, Himmetoglu S, Dincer Y, Koc EE, Hatipoglu S, et al. DNA damage and glutathione level in children with asthma bronchiale: Effect of antiasthmatic therapy. Pediatr Allergy Immunol 2010;21:e674-8.

73. Ammit AJ, Panettieri RJ. Invited review: The circle of life: Cell cycle regulation in airway smooth muscle. J Appl Physiol 2001;91:1431-7.

74. Puddicombe SM, Torres-Lozano C, Richter A, Bucchieri F, Lordan JL, Howarth PH, et al. Increased expression of p21(waf) cyclin-dependent kinase inhibitor in asthmatic bronchial epithelium. Am J Respir Cell Mol Biol 2003;28:61-8.

75. Fedorov IA, Wilson SJ, Davies DE, Holgate ST. Epithelial stress and structural remodelling in childhood asthma. Thorax 2005;60:389-94.

76. Mukhopadhyay NK, Weisberg E, Gilchrist D, Bueno R, Sugarbaker DJ, Jaklitsch MT, et al. Effectiveness of trichostatin A as a potential candidate for anticancer therapy in non-small-cell lung cancer. Ann Thorac Surg 2006;81:1034-42.

77. Ame JC, Spenlehauer C, de Murcia G. The PARP superfamily. Bioessays 2004;26:882-93.

78. Bouchard VJ, Rouleau M, Poirier GG. PARP-1, a determinant of cell survival in response to DNA damage. Exp Hematol 2003;31:446-54.

79. Chiarugi A, Moskowitz MA. PARP-1-A perpetrator of apoptotic cell death? Gene 2002;9:11.

80. Yelamos J, Oliver FJ. Role of poly (ADP-ribose) polymerase-1 (PARP-1) in the inflammatory response. Inmunologia 2002;21:219-27.

81. Tezcan G, Gurel CB, Tutluoglu B, Onaran I, Kanigur-Sultuybek G. The Ala allele at Val762Ala polymorphism in poly (ADP-ribose) polymerase-1 (PARP-1) gene is associated with a decreased risk of asthma in a Turkish population. J Asthma 2009;46:371-4.

82. Aoshiba K, Zhou F, Tsuji T, Nagai A. DNA damage as a molecular link in the pathogenesis of COPD in smokers. Eur Respir J 2012;39:1368-76.

83. Weseler AR, Geraets L, Moonen HJ, Manders RJ, van Loon LJ, Pennings HJ, et al. Poly (ADP-ribose) polymerase-1-inhibiting flavonoids attenuate cytokine release in blood from male patients with chronic obstructive pulmonary disease or type 2 diabetes. J Nutr 2009;139:952-7.

84. Geraets L, Moonen HJ, Brauers K, Gottschalk RW, Wouters EF, Bast A, et al. Flavone as PARP-1 inhibitor: Its effect on lipopolysaccharide induced gene-expression. Eur J Pharmacol 2007;573:241-8.

85. Havranek T, Aujla PK, Nickola TJ, Rose MC, Scavo LM. Increased poly (ADP-ribose) polymerase (PARP)-1 expression and activity are associated with inflammation but not goblet cell metaplasia in murine models of allergen-induced airway inflammation. Exp Lung Res 2010;36:381-9.

86. Oumouna M, Datta R, Oumouna-Benachour K, Suzuki Y, Hans C, Matthews K, et al. Poly (ADP-ribose) polymerase-1 inhibition prevents eosinophil recruitment by modulating Th2 cytokines in a murine model of allergic airway inflammation: A potential specific effect on IL-5. J Immunol 2006;177:6489-96.

87. Lucarini L, Pini A, Gerace E, Pellicciari R, Masini E, Moroni F. Poly (ADP-ribose) polymerase inhibition with HYDAMTIQ reduces allergen-induced asthma-like reaction, bronchial hyper-reactivity and airway remodelling. J Cell Mol Med 2014;18:468-79.

88. Mehrotra P, Riley JP, Patel R, Li F, Voss L, Goenka S. PARP-14 
functions as a transcriptional switch for Stat6-dependent gene activation. J Biol Chem 2011;286:1767-76.

89. Goenka S, Kaplan MH. Transcriptional regulation by STAT6. Immunol Res 2011;50:87-96.

90. Kuperman DA, Schleimer RP. Interleukin-4, interleukin-13, signal transducer and activator of transcription factor 6 , and allergic asthma. Curr Mol Med 2008;8:384-92.

91. Sehra S, Bruns HA, Ahyi ANN, Nguyen ET, Schmidt NW, Michels EG, et al. IL-4 Is a Critical Determinant in the Generation of Allergic Inflammation Initiated by a Constitutively Active Stat6. J Immunol 2008;180:3551-9.

92. Kuperman D, Schofield B, Wills-Karp M, Grusby MJ.
Signal transducer and activator of transcription factor 6 (Stat6)-deficient mice are protected from antigen-induced airway hyperresponsiveness and mucus production. J Exp Med 1998; 187:939-48

93. Akimoto T, Numata F, Tamura M, Takata Y, Higashida N, Takashi T, et al. Abrogation of bronchial eosinophilic inflammation and airway hyperreactivity in signal transducers and activators of transcription (STAT) 6-deficient mice. J Exp Med 1998; 187:1537-42.

94. Mehrotra P, Hollenbeck A, Riley JP, Li F, Patel RJ, Akhtar N, et al. Poly (ADP-ribose) polymerase 14 and its enzyme activity regulates $\mathrm{T}(\mathrm{H}) 2$ differentiation and allergic airway disease. J Allergy Clin Immunol 2013;131:521-31. 